\title{
Internet: \\ Desafio para uma Contabilidade Interativa
}

\author{
Armando Catelli \\ Professor Doutor do Departamento de \\ Contabilidade e Atuária da FEA/USP \\ Coordenador do Núcleo Gecon/FIPECAFI/FEA/USP
}

\author{
Edilene Santana Santos \\ Mestre e Doutoranda em Controladoria e \\ Contabilidade pela FEA/USP \\ Pesquisadora da Fipecafi - Núcleo Gecon
}

RESUMO

O fenômeno explosivo da Internet, insuspeitado há 10 anos, e que hoje se expande de modo acelerado e abrangente em todas as atividades humanas, tem impactos relevantes também na contabilidade.

A interatividade, como característica da nova forma de comunicação inaugurada com a Internet, apresenta desafios ao Sistema Contábil Gerencial, cujas respostas, na forma de uma visão interativa da empresa, do patrimônio e do processo de gestão, se expressam na abordagem do Sistema de Gestão Econômica.

As insuficiências da Contabilidade Financeira em expressar a realidade das empresas da nova economia no mercado de capitais são igualmente identificadas. Ao mesmo tempo, são comentadas as oportunidades que se abrem à contabilidade financeira, com a divulgação das demonstrações mediante os recursos de linguagem da Internet, com base nos projetos desenvolvidos por entidades reguladoras, particularmente pelo International Accounting Standards Committee (IASC).

Com o incremento da comunicação contábil interativa via Internet e com o aprofundamento do debate sobre a contabilização das empresas de ativos intelectuais intensivos, como as da nova economia, preconiza-se, sob a égide da interatividade, uma renovação da Contabilidade Financeira e sua maior aproximação da Contabilidade Gerencial, com base nos fundamentos da Teoria Contábil.

Palavras-chave: Internet, Contabilidade Gerencial, Contabilidade Financeira
ABSTRACT

The explosive phenomenon of the Internet, which was unsuspected ten years ago, and is now expanding in an accelerating and involving way in all human activities, has a relevant impact on accounting as well.

Interactivity - one characteristic of the new communication form that was inaugurated by the Internet - raises challenges for the Management Accounting System, whose answers, in the form of an interactive view of the enterprise, its assets and its managing process, are expressed in the approach of the Economic Management System.

The insufficiency of Financial Accounting to express the reality of the new economy's enterprises in the capital markets is identified. At the same time, we comment on the new opportunities for Financial Accounting, opened up by the presentation of reports with use of Internet resources, based on projects developed by regulatory entities, particularly the IASC.

With the increase of interactive accounting communication via Internet and the deepening of the intellectually intensive assets, like the new economy's ones, a renewal of Financial Accounting and its narrower approach to Management Accounting is expected to occur, under the aegis of interactivity and well-founded on Accounting Theory.

Key words: Internet, Management Accounting, Financial Accounting. debate about the accounting of enterprises with

NOTA: Artigo publicado nos Anais do XVI Congresso Brasileiro de Contabilidade - Goiânia - GO, out/2000, em cd rom. 


\section{INTRODUÇÃO}

O fenômeno da Internet, para toda a comunidade contábil contemporânea, como, aliás, para toda a sociedade humana, é ainda uma experiência nova, surpreendente, avassaladora e, pelas transformações que traz consigo, inquietante. Todos se recordam que há apenas 8 anos a Internet simplesmente não existia. O primeiro uso público da Web para pesquisadores a partir do site do Conselho Europeu de Pesquisas Nucleares - CERN, de Genebra, ocorreu apenas em janeiro de 1992 (Jamsa et al., 1999, p. 5).

A partir dessa inauguração, a expansão exponencial da Internet revelou-se como o fato mais marcante da década. Um ano e meio depois, em 1993, já havia sessenta servidores da Web; em 1999 já eram mais de 1 milhão (id., p.6) e atendiam a mais de 150 milhões de usuários (Gurovitz, 1999a, p.151).

Hoje, o impacto da Internet na economia dificilmente poderia ser superestimado, pois essa nova tecnologia e forma de comunicação penetra em todas as atividades humanas: nas fábricas, nas transportadoras, nos armazéns, nas distribuidoras, no comércio atacadista e varejista, na agricultura, nos hospitais, na administração pública, nas profissões liberais e serviços em geral, nas telecomunicações, na publicidade, na mídia, nas escolas e atividades de todos os níveis educacionais e científicos.

O impacto econômico apenas do comércio eletrônico - considerado por Peter Drucker o mais importante fenômeno dentro da Internet (Drucker, 2000, p.113) - que mal começara em 1996 e em 1998 já movimentava US $\$ 80$ bilhões, será este ano de quase US\$ 400 bilhões e, em 2003, mais de US\$ 3 trilhões (Gurovitz, id., p. 151), superando o valor do PIB atual individual de quase todos os países do mundo.

Embora em muitas empresas o percentual do faturamento relativo ao e-commerce seja ainda pequeno, noutras empresas, que se adaptaram à Internet, esse percentual já é expressivo. A Dell, por exemplo, fabricante de computadores, já vende diariamente US\$18 milhões pela Internet, perto de $30 \%$ do seu faturamento. Em 2000, a Cisco pretende vender US $\$ 10$ bilhões, e a IBM, após grande esforço de transformação, espera faturar US\$ 15 bilhões, com o e-commerce (Gurovitz, 1999b, p.132 e 138).

Que as transformações causadas pela Internet estão apenas no início, como nota Drucker (id. p;113126), pode-se inferir a partir das novas tecnologias, que já estão sendo introduzidas: os serviços de alta velocidade e de banda larga; a transmissão de voz, som e imagem dinâmica em tempo real; a integração entre o computador e o aparelho de televisão; a Internet sem fio através de celulares (que, estimase, dentro de 3 anos terá mais usuários que os acessos pela rede convencional); ${ }^{1}$ e outras inovações, como a Internet em carros inteligentes da General Motors (Informationweek, 1999, p. 153-154); a Internet popular em orelhões públicos como o projeto da Tele Centro Sul (Vasconcelos, 2.000, p.3); a Internet a partir de aparelhos eletrodomésticos, como as geladeiras Screenfridge da sueca Electrolux (Peterson, 2000, p.42) e, talvez em breve, até em chips embutidos nas vestes dos usuários.

Todos esses fatos e perspectivas criam entre os estudiosos a consciência de quão profunda e abrangente é a transformação em curso das atividades humanas, provocada pelo advento da Internet. A esse respeito, como cita Gurovitz (1999a, p.153s), o vice-reitor da Sloan School of Management do MIT (Instituto de Tecnologia de Massachusetts), o brasileiro Gabriel Bitran, comenta:

Ninguém esperava ver isso tão rapidamente. $A$ profundidade da transformação vai se tornar mais evidente em breve. Ainda não podemos nem conceber o que é possível. Nesse mundo, a distância física é irrelevante. A única distância será o tempo.

Do mesmo modo, observa Drucker (2000, p. 48): O aparecimento explosivo da Internet (...) está modificando profundamente economias, mercados e estruturas setoriais; os produtos e serviços e seu fluxo; a segmentação, os valores e o comportamento dos consumidores; 0 mercado de trabalho. O impacto, porém, pode ser ainda maior nas sociedades e nas políticas empresariais e, acima de tudo, na maneira como encaramos o mundo e nós mesmos dentro dele.

Parece inegável que a Internet, ao transformar o conjunto das atividades humanas, não deixará de impactar profundamente a ciência e prática contábil.

Com efeito, os estudiosos identificam, no

${ }^{1}$ Ver Internet 2.000. Veja Vida Digital. Ano 33, n $1645,19 / 04 / 2000$. 
desenvolvimento dos conceitos, métodos e práticas da contabilidade, respostas progressivas aos desafios representados pelas transformações que ocorrem na história dos negócios, das organizações, da economia e da sociedade.

Como nota ludícibus (1992, p.44), "através dos tempos, verifica-se que normalmente o grau de avanço da contabilidade está diretamente associado ao grau de progresso econômico, social e institucional de cada sociedade".

Littleton \& Zimmerman (1962, p.2), ao estudar a evolução da teoria contábil, colocam a questão: "que pressões poderiam ter produzido, tão cedo na história da humanidade, uma metodologia de tal potencial?" E constatam que "os métodos não acontecem simplesmente; eles são intencionalmente inventados. Por trás das ações construtivas estão idéias ou conceitos que envolvem as necessidades, os propósitos e as conveniências", que evoluem no tempo.

De fato, desde o seu surgimento, os empreendimentos voltados para a Internet desafiaram os padrões tradicionais de gestão, como já acontecera com as empresas de software e computação, como a Apple $^{2}$ ou Microsoft ${ }^{3}$. As empresas da nova economia, integradas em grande parte por jovens informais e irreverentes, tiveram por foco, desde seu início, a inovação e a criatividade, fugindo às práticas usuais das empresas tradicionais. Desse modo, puderam abordar produtos, mercados e usuários até então desprezados ou pouco conhecidos - e implantando aceleradamente a nova forma de comunicação interativa que tem sido a razão do seu sucesso.

Essas características das empresas da Internet e a originalidade de seus produtos e métodos interativos trazem consigo uma visão de empresa e modelos de gestão inovadores. A abordagem patrimonial dessas empresas, diante de um mercado tão novo e de um futuro promissor, mas incerto, parece não se enquadrar perfeitamente nos parâmetros usuais de mensuração. Essas peculiaridades constituem certamente um desafio à contabilidade gerencial, já empenhada, há anos, na recuperação de sua relevância perdida, apontada por Johnson \& Kaplan (1990).

Diante do mercado de capitais, o comportamento vertiginoso das empresas da Internet - mesmo descontando exageros e euforias conjunturais do mercado, que provavelmente ocasionarão a mortalidade de várias dessas empresas ${ }^{4}$ - parece revelar a inaplicabilidade a essas empresas dos critérios habituais de avaliação e criação de expectativas. A nova escala de discrepâncias entre o valor das ações e os balanços dessas empresas ressalta, mais do que já vem ocorrendo com as demais empresas, a inadequação dos princípios contábeis atuais para expressar a realidade econômica dessas entidades.

Por outro lado, os recursos tecnológicos crescentes da Internet e as mudanças de hábitos que eles provocam nas empresas e na sociedade oferecem à contabilidade as novas oportunidades da velocidade e interatividade, possibilitando um grau de flexibilidade e precisão da informação, em tempo real, até há poucos anos impensável para o sistema de informações.

Este trabalho tem por objetivo examinar alguns desafios e oportunidades que a Internet representa para a Contabilidade, tanto voltada para a gestão, quanto dirigida ao mercado de capitais.

Primeiramente serão identificadas as novas questões e abordagens levantadas pelas empresas e pelo fenômeno global da Internet junto ao sistema de informação gerencial, à luz dos princípios e critérios do Sistema de Gestão Econômica ${ }^{5}$.

A seguir serão examinadas as implicações do aparecimento das empresas da nova economia para a contabilidade financeira, particularmente com vistas ao mercado de capitais.

As novas perspectivas de apresentação e

\footnotetext{
2 Sobre o papel da Apple, dentro da administração americana, na evolução da informação interativa, ver Locke (1999, p.1-13).

${ }^{3}$ Mintzberg \& Quinn (1996, p.503-516) comentam a informalidade de funcionários da Microsoft, que não possuem horários de trabalho pré-estabelecidos, trabalham em fins de semana e saem do escritório de madrugada para tocar guitarra no pátio da empresa, interessados apenas em atingir os objetivos da sua atividade com eficácia.

${ }^{4}$ Vieira (2000, p.1) comenta a afirmação de Sanford Weill, presidente do Citi group, de que nos próximos 5 anos $80 \%$ das empresas da Internet, listadas na Nasdaq desaparecerão e as $20 \%$ restantes valerão mais do que todas juntas. Teixeira $(2000,42-52)$ comenta a chegada do choque da realidade na Internet e o fim da euforia do mercado, com a necessária seleção "darwinista" das empresas.

5 A Gestão Econômica é um sistema de informação gerencial de vanguarda, desenvolvido na FEA-USP (Núcleo Gecon), com sucesso comprovado mediante consultoria a empresas de expressão, e que já produziu numerosos e reconhecidos trabalhos acadêmicos. Para maiores informações, consultar o site www.gecon.com.br.
} 
divulgação das informações contábeis via Internet serão, finalmente, comentadas com base no documento Business Reporting on the Internet do IASC, produzido em novembro de 1999, bem como em outros projetos do Financial Accounting Standards Board (FASB) e de outras entidades.

Pretende-se mostrar que a superação dos desafios e o aproveitamento das oportunidades oferecidas pela Internet constituem um impulso para o aperfeiçoamento da informação contábil, e sua melhor adequação aos usuários internos e externos, na forma do que se poderia chamar de uma contabilidade interativa.

\section{1 - A INTERNET E A CONTABILIDADE GERENCIAL}

\section{1 - A Empresa Interativa}

Ao dar um simples click no mouse para acessar a Internet, o usuário - seja consumidor, gestor, parceiro ou colaborador de uma empresa - sabe que está se comunicando com a rede das redes dos computadores do mundo, que constitui a Internet, e está se integrando no conjunto de sistemas e padrões de intercomunicação pela Internet que formam a estrutura da World Wide Web. Este usuário sabe que o seu simples gesto o torna participante ativo desse grande e complexo sistema, do qual também fazem parte centenas de milhões de usuários em milhões de grupos, empresas e organizações.

Para os integrantes de uma empresa, o acesso a esse grande sistema faz com que se acelerem e se intensifiquem as intercomunicações, em tempo real, tanto internas ao seu micro-sistema empresarial, muitas vezes dotado de Intranets, quanto, de inúmeras formas, com o macro-sistema ambiental.

Essa intercomunicação cada vez mais intensa e generalizada dentro das empresas e destas com o ambiente expressa, numa nova dimensão, a realização do que autores como Ackoff (1974, p.12ss) caracterizam como sistema: um conjunto de dois ou mais elementos tais que cada elemento influencie todo o conjunto e seja afetado por pelo menos outro elemento, de modo que nenhum elemento seja independente do todo e o conjunto total não possa ser desmembrado em conjuntos independentes.

A interatividade possibilitada pela Internet ressalta, assim, a empresa como sistema aberto e dinâmico, constituído por subsistemas interdependentes, que se relacionam continuamente entre si e com o sistema ambiente, tendo em vista um objetivo comum, como caracterizado por Guerreiro:

Através do desempenho de suas funções, a empresa encontra-se em um processo interativo contínuo com o meio ambiente, obtendo recursos, transformando-os em produtos e atendendo aos seus objetivos. Esse processo desenvolve-se a partir da interação entre seus subsistemas, ou seja, as pessoas (subsistema social), condicionadas por determinados princípios (subsistema institucional), ocupando determinados postos com autoridade e responsabilidade pré-definadas (subsistema formal), tomam decisões (subsistema de gestão) sobre recursos (subsistema físico), utilizando informações (subsistema de informação), para que a empresa alcance seu objetivo (Guerreiro, 1989, p.154).

Essas características das empresas como sistemas interativos são certamente intensificadas pelo uso da Internet dentro e fora da empresa, e se expressam particularmente nos empreendimentos da nova economia. Sobretudo porque essas empresas têm por integrantes principais os chamados "trabalhadores do conhecimento", dotados de alto nível educacional e capazes de maior autonomia e coordenação - e, portanto, se afastam dos modelos de gestão mais coercitivos da empresa tradicional.

Nesse sentido, as empresas da nova economia ensejam um modelo de gestão por áreas ou centros de responsabilidade, as quais, na Gestão Econômica, "podem ser vistas como pequenas empresas dentro da organização, com missão e objetivos próprios (...), em consonância com os interesses globais da empresa" (Pereira, 1993, p. 122).

Druker (1992, p. 208) já havia previsto para o final do século XX a "transformação de gerentes funcionais em gerentes de negócios, cada um com um papel específico, mas todos membros da mesma produção e do mesmo elenco".

O mesmo autor, recentemente (id., 2000, p.126), confirma e leva mais adiante esse mesmo pensamento, preconizando, na era da Internet, a valorização social e a parceria empresarial do trabalhador do conhecimento.

Essa visão do gerenciamento com autonomia, 
iniciativa e responsabilidade é própria da Gestão Econômica, como observa Catelli (1999, p.31):

O modelo Gecon estrutura-se com base em um entendimento da missão da empresa, do conjunto de crenças e valores da organização, da estrutura organizacional, da realidade operacional e das características dos gestores empresariais. (...)

As áreas [são] tratadas como empresas, seus gestores como os respectivos "donos", e a avaliação dos mesmos envolve não só os recursos consumidos (custos), como também os produtos/serviços gerados (receitas). Assim sendo, objetiva-se destacar e valorizar posturas empreendedoras.

Nesse sentido, a Internet vem somar-se aos processos interativos de gestão cada vez mais incentivados nas empresas recentemente, que visam, mediante intensa comunicação, à ruptura de barreiras internas e com o ambiente, de modo a possibilitar a todos os seus integrantes a identificação com os objetivos e o sucesso da organização. Tais são, por exemplo, o projeto "empresa sem fronteiras", da GE (Tichy \& Sherman, 1993, p.205) e o sistema de produção enxuta, do tipo Toyota, por equipes interfuncionais atuando por produtos no chão da fábrica, adotado na Pratt \& Whitney, Porsche e na Volkswagen em Resende, entre outras (Womack \& Jones, 1998, p. 165ss).

Quão vital tem sido para as empresas a necessidade de incrementar os seus processos interativos transparece do programa do presidente da GE, Jack Welch. Para essa empresa, então com 350.000 empregados, para a década de 90 - e que foi efetivamente implementado ${ }^{6}$ :

Nosso sonho para a década de 90 é uma empresa sem fronteiras, uma empresa onde as paredes que nos separam internamente uns dos outros e externamente de nossos clientes sejam derrubadas. A empresa sem fronteiras que prevemos eliminará as barreiras entre engenharia, produção, marketing, vendas e serviço ao cliente. Ela não identificará distinções entre operações "domésticas" e "estrangeiras" - nos sentiremos tão à vontade fazendo negócios em Budapeste e Seul quanto nos sentimos em Louis Ville e Schenectady. Uma organização sem fronteiras ignorará ou eliminará títulos de grupos como "gerência", "mensalistas" ou "horistas", que representam obstáculos ao trabalho em equipe. Uma empresa sem fronteiras derrubará também suas paredes externas, alcançando os principais fornecedores e transformando-os em parte de um processo único no qual eles e nós daremos as mãos e juntaremos nossas mentes com um só objetivo - a satisfação do cliente (Tichy \& Sherman, 1993, p.205).

Dificilmente, entretanto, o modelo de gestão das empresas tradicionais comporta o grau de interatividade requerido para um projeto voltado para a Internet. Por isso, muitas vezes, as empresas tradicionais preferem criar "entidades.com" separadas das demais unidades de negócio do grupo (Rebouças, 2000, p.132-138), dotadas do modelo de gestão que permita o seu sucesso no ambiente extremamente dinâmico da nova economia.

A postura empreendedora, ressaltada pelos modernos sistemas de gestão e grandemente favorecida pela interatividade da Internet, gera inegavelmente um impacto na abordagem contábil das empresas. Não se pode conceber, por exemplo, a autonomia e a interatividade dos integrantes da empresa entre si e com o ambiente, sem que o sistema de informação gerencial Ihes possibilite, ao contrário do que ocorre nas empresas tradicionais, voltar-se pró-ativamente para a obtenção de resultados.

Parece claro que as empresas tradicionais tenderão a transformar-se para adquirir a postura próativa e dinâmica dos empreendimentos da Internet.

Segundo uma pesquisa com 525 executivos de diversos setores, $90 \%$ dos consultados esperam da Internet um impacto substancial ou transformador na sua estratégia corporativa. Consultores da Booz Allen \& Hamilton, a esse respeito, observam: "para competir de modo eficaz na Era Digital, as empresas terão de fazer seus modelos de negócios evoluírem das cansativas hierarquias de comando e controle desenvolvidas na Era Industrial para as organizações digitais, comuns entre as empresas que nasceram com a Internet". Em alguns casos, como o dos

\footnotetext{
${ }^{6}$ Sobre o esforço e o resultado desta transformação, ver Tichy \& Sherman, 1993, p. 216ss. Ver também www.ge.com
} 
fabricantes de hardware, o uso da interatividade propiciada pela Internet aumentou a produtividade em 42\% ao ano, entre 1995 e 1999, quando na economia americana a produtividade cresceu apenas 2,2\% ao ano desde 1996 - após a popularização da Internet - contra um crescimento anterior de apenas $1 \%$ ao ano (Gurovitz, 1999b, p. 127).

Embora pareçam exageradas, certas afirmações categóricas precisam ser consideradas, como a previsão de Lou Gerstner, da IBM, para quem as atuais empresas da Internet são apenas precursoras, como vaga-lumes antes da tempestade: "a tempestade que está chegando - a verdadeira perturbação na força - será quando os milhares e milhares de instituições que existem hoje agarrarem o poder dessa infra-estrutura global de computação e comunicação e usarem-no para transformar a si próprias. Essa será a verdadeira revolução". Ou a de Andy Grove da Intel: "em cinco anos, todas as empresas serão empresas da Internet ou simplesmente não serão empresas" (id., p. 138 e 126).

Assim, o fenômeno recente da Internet lança uma nova luz às previsões feitas por Peter Drucker há dez anos, para a empresa do ano 2000. Não é coincidência que esse autor preconize ao mesmo tempo os modelos de gestão interativos e uma nova abordagem da contabilidade.

Referindo-se especificamente à manufatura, esse autor comenta:

A fábrica de hoje é um couraçado. A fábrica de 1999 será uma 'flotilha', consistindo de módulos concentrados ao redor de um estágio no processo de produção, ou ao redor de um certo número de operações intimamente relacionadas. Embora ainda continue existindo um comando e controle geral, cada módulo terá seu próprio comando e controle. E cada um deles, como os barcos de uma flotilha, será manobrável, tanto em termos de sua posição no processo como um todo, como do seu relacionamento com os outros módulos. Essa organização (...) permitirá rápidas mudanças em esquemas e produtos (Drucker, 1992, p.205).

Que esse novo grau de inter-relacionamento demanda uma nova abordagem da contabilidade, observa o mesmo autor, ao preconizar

uma nova contabilidade de manufatura, que seria melhor chamada de 'economia da manufatura' [e que] difere radicalmente da contabilidade de custos tradicional em seus conceitos básicos. Seu propósito é integrar a manufatura com a estratégia de negócios (id., p.202).

É de notar que essa previsão de Drucker, publicada pela primeira vez em 1990, não levava em conta a irrupção explosiva da interatividade mediante a Internet, poucos anos depois - o que, hoje, mais ressalta o seu impacto na "nova contabilidade", vislumbrada pelo autor.

A Internet parece constituir, assim, um desafio que pode dar origem a uma "nova era de expansão construtiva do potencial da contabilidade", hipótese aventada por Littleton \& Zimmerman (1962, p.252), para o final do século $X X$.

De fato, esses autores constatam na evolução da contabilidade eras de desenvolvimento acelerado sob pressão de fenômenos econômicos e empresariais, entre as quais a partida dobrada dos italianos do século XV, a apresentação de dados financeiros dos balanços ingleses do século XIX e a contabilidade industrial de custos dos americanos no século XX.

Mais recentemente, Johnson \& Kaplan (1990, p.183ss), propugnaram a recuperação da relevância perdida da contabilidade gerencial, marcada por obsolescência diante dos impactos da competição global, do progresso tecnológico, dos novos sistemas de controle de qualidade total (TQC), de just in time (JIT), de manufatura integrada por computação (CIM), pela desregulamentação dos transportes e serviços e pelo fluxo de capitais nas transações internacionais.

Diante dessas novas necessidades, os autores preconizam um sistema gerencial que, apoiado na "enorme expansão da capacidade de computação" (id., p.5), constitua um elo de comunicação descentralizada de ida e volta entre os gestores de vários níveis da organização (id., p.4).

Esses autores, entretanto, publicando sua primeira edição em 1987 - e tendo como foco as necessidades de renovação dos sistemas gerenciais das grandes corporações tradicionais - ainda não suspeitavam do imenso avanço da Internet que emergiria ${ }^{7}$ apenas nos anos seguintes, com seus novos desafios à contabilidade.

\footnotetext{
${ }^{7}$ De fato, a Internet, dentro do círculo restrito de pesquisadores de sua precursora, a ARPAnet (da Advanced Research Projects Agency do Departamento de Defesa norteamericano), já existia desde 1969. Mas a Web foi criada por Tim Berners-Lee, então pesquisador do CERN (Conseil European pour la Recherche Nucleaire - Conselho Europeu de Pesquisa Nuclear), apenas em março de 1989 (Jamsa et al., 1999, p.5; Dyson, 1998, p.4-5).
} 
Hoje, com o desenvolvimento crescente da Internet, a visão da empresa como sistema interativo e pró-ativo, voltado para resultados, implica o afastamento de posturas e princípios da contabilidade tradicional, de modo a possibilitar a integração de sólidos parâmetros econômicos ao sistema de informação gerencial.

A Gestão Econômica, ao adotar tais parâmetros, proporciona uma visão interativa do patrimônio, que se exprime nitidamente na trajetória atual das empresas e do fenômeno da Nova Economia.

\section{2 - A Visão Interativa do Patrimônio}

A Contabilidade, como visão integradora dos negócios, tal como estudada por Littleton \& Zimmerman (1962) e outros autores ${ }^{8}$ representa mensuração das relações da empresa com o ambiente e, nesse sentido, sempre buscou uma visão patrimonial interativa.

As relações específicas que caracterizaram os negócios nas diversas épocas foram sendo progressivamente incorporadas à metodologia e prática contábil. Assim, a visão contábil do patrimônio se baseia nos inventários e nas transações comerciais, desde o tempo de Luca Pacioli, até o início do século XIX. Com a Revolução Industrial, tornam-se relevantes as transações internas das organizações, muitas vezes específicas aos diversos tipos de atividade como as ferrovias, as empresas de telégrafo, as incipientes redes de distribuição e as indústrias recém-surgidas. O sistema gerencial passava a centrar-se na atividade operacional chave da organização. Ao mesmo tempo, como anteriormente mencionado, a partir da Inglaterra, a visão contábil passou a enfatizar as informações financeiras dos balanços, com vistas aos usuários externos. No início do século $X X$, a expansão da manufatura traz consigo a contabilidade industrial de custos. A verticalização e diversificação das grandes organizações como a Du Pont e a General Motors trazem a questão do investimento de grandes capitais e a abordagem específica do ROI (Johnson \& Kaplan, 1990, p. 6-12).

Desde a década de 60 , muito se tem discutido sobre a validade das práticas contábeis atuais para a produção de informações relevantes para a tomada de decisões econômicas. A publicação de Relevance Lost por Johnson \& Kaplan, no final da década de 80 , impulsionou uma nova onda de críticas à contabilidade gerencial, por demais atrelada aos preceitos da contabilidade financeira e fixada em modelos que tiveram validade apenas no início do século.

De fato, embora tenha havido esforços no sentido de resgatar a relevância perdida, a maioria dos modelos propostos não tocou no ponto crucial da perda de relevância da contabilidade para gestão, qual seja, o modelo de mensuração subjacente à avaliação do patrimônio.

O aparecimento explosivo dos empreendimentos de Internet parece ter vindo reacender esse debate, demonstrando quão pouco se tem progredido nas últimas duas décadas no desenvolvimento de conceitos e práticas contábeis adequadas à gestão dos negócios.

Com efeito, tais empresas se encontram em fase de lançamento e crescimento do ciclo de vida do seu negócio, em meio a um mercado pujante, mas desconhecido, porque ainda se está apenas formando. A prioridade do gerenciamento dessas empresas não pode ser, portanto, concentrar-se nos custos, como insistem ainda os modelos de contabilidade gerencial - embora os custos sejam sempre importantes - mas sim investir aceleradamente no ganho de posições nesse novo mercado.

A preocupação dessas empresas também não é ainda a apresentação de lucros nos seus balanços no curto prazo, os quais ocorrem normalmente na fase de maturidade, embora algumas empresas de Internet, como a Amazon, que existe já há 5 anos, estejam sendo insistentemente cobradas para ingressarem na trilha verde dos lucros distribuíveis. ${ }^{9}$

Para analisar essas empresas, é crucial o conceito de ativo como potencial de lucros futuros, já reconhecido na teoria contábil, e adotado na Gestão Econômica, mas que não encontra ainda respaldo nos sistemas gerenciais tradicionais. É de se admirar que ainda não tenha sido perfeitamente assimilado o

\footnotetext{
${ }^{8}$ Ver, por exemplo, Matessich (1964) e Ijiri (1967) para a mensuração contábil como representação integrativa das transações.

${ }^{9}$ A Amazon teve seu início em julho de 1995. Ver www.amazon.com e a entrevista de Jeff Bezos, da Amazon, à rede Bloomberg em 16/07/2000.
} 
conceito de ativo definido pelo AAA (American Accounting Association), já em 1957:

Conceitualmente, a medida de valor de um ativo é a soma dos preços futuros de mercado dos fluxos de serviços a serem obtidos, descontados pela probabilidade de ocorrência e pelo fator juro, a seus valores atuais (apud ludícibus, 1997, p.125).

Tal conceito, com efeito, expressa a relação da empresa com o seu futuro, como constitutiva do seu patrimônio, e essa relação, essa interação entre o presente e o futuro, tem escapado à visão patrimonial da contabilidade gerencial. Mas sem o reconhecimento dessa interação no tempo, a contabilidade será cada vez menos capaz de expressar a realidade das empresas e mercados inovadores, cada vez mais freqüentes no mundo em mudanças da nova economia.

Além disso, o fato de as empresas da Internet, mais do que outras empresas, trabalharem predominantemente com o conhecimento, torna-as pouco acessíveis à contabilização gerencial tradicional, ainda presa aos parâmetros da contabilidade financeira, a qual reconhece os ativos intangíveis na forma do goodwill apenas quando tal ativo é adquirido.

Com efeito, como observa Oliveira (1999, p.125), a formação dos intangíveis é "a idéia central, o gene", das empresas centradas no conhecimento:

As empresas que atuarão nesse novo ambiente, qualquer que seja sua forma de organização, organizações virtuais ou redes econômicas, compartilham a mesma lógica da economia do conhecimento: as idéias, conhecimento, capacidade de processar informação, e outros intangíveis - como o capital humano, goodwill com clientes geram riquezas muito mais rapidamente e a um custo muito menor do que os ativos tangíveis faziam.

Como nota o autor, é cada vez maior a importância dos intangíveis nessas empresas. Por exemplo, no começo de 1996, para cada US $\$ 100$ investidos na IBM, US\$23 correspondiam a ativos tangíveis (ou seja, US\$16,6 bilhões de ativos líquidos para um valor de mercado de US $\$ 70,7$ bilhões); os mesmos US\$100 investidos na Microsoft correspondiam apenas a US\$ 1 em ativos tangíveis (US\$ 930 milhões de ativos tangíveis para US $\$ 85,5$ bilhões de valor de mercado).

Poder-se-ia perguntar até que ponto será admissível ou tolerável à prática contábil continuar a negligenciar a questão dos intangíveis e, com eles a contribuição do conhecimento à riqueza das empresas e, com isso, ignorar a interação do futuro com o presente na avaliação do patrimônio.

Dentro da visão da empresa como sistema interativo voltado para a obtenção de resultados, própria da Gestão Econômica, o reconhecimento do goodwill é fundamental para a mensuração do seu patrimônio. O que torna uma empresa capaz de obter resultados e, portanto, de gerar riqueza, é prioritariamente o goodwill, como combinação dos seus conhecimentos, habilidades, experiência e, sobretudo, o seu modelo de gestão. É o goodwill que constitui, principalmente, a capacidade de a empresa, como subsistema, interagir eficazmente com o macro-sistema ambiente. É essa capacidade que a conduz às decisões acertadas, pelas quais a empresa, já no presente, antecipa de algum modo a criação futura de valor, aumentando o valor do seu patrimônio.

Assim, o conceito de ativo como potencial gerador de riqueza é específico a cada empresa, uma vez que depende da inserção desse ativo no conjunto dos demais ativos da empresa e, sobretudo, no conjunto dos conhecimentos e habilidades que formam o seu goodwill. De nada adiantaria um equipamento de alta tecnologia numa empresa em que ninguém sabe usá-lo.

Isso é válido para todas as empresas, inclusive aquelas dotadas de grandes ativos fixos. Drucker (1992, p.205) cita o caso do investimento da General Motors em automação no valor de US\$ 30 ou US $\$ 40$ bilhões que produziu diminuição de eficiência e aumento de custos em relação aos concorrentes $^{10}$.

É, assim, esclarecedora a afirmação de Martins (1972, p.30): "O potencial de resultado econômico é a verdadeira caracterização de um elemento como ativo, e não só isso, considerâmo-lo como sendo ele próprio o real ativo de uma entidade".

${ }^{10}$ Ver Catelli et al (1999, p.2). 
Do mesmo modo comenta ludícibus (1997, p. 125), a propósito do conceito de ativo do AAA:

Pelo fato de os ativos serem recursos econômicos alocados às finalidades do negócio, dentro de um período específico de tempo, e sendo agregados de potenciais de serviços disponíveis ou benéficos para as operações da entidade, o significado de alguns ativos somente pode ser relacionado aos objetivos da entidade e dependerá da continuidade desta.

Dentro desse conceito de ativo, a Gestão Econômica adota critérios econômicos para mensuração do lucro e do valor do patrimônio da empresa. Esses são inseparáveis, pois o lucro é o benefício gerado pelo patrimônio, o qual, por sua vez, é mensurado pelo fluxo de benefícios futuros que pode gerar, reduzidos a valor presente ${ }^{11}$.

Assim, observa Guerreiro (1992, p.5):

Em termos econômicos, o lucro é visto como a quantia máxima que a firma pode distribuir como dividendos e ainda continuar tão bem ao final do período como estava no começo. Continuar tão bem, economicamente falando, é interpretado como manter o capital intacto em termos do valor descontado do fluxo de recebimentos líquidos futuros. O lucro econômico é gerado, portanto, assim que exista um aumento no patrimônio líquido. Por outro lado, para mensurar o lucro como incremento do patrimônio líquido é necessária a avaliação de todos os ativos da empresa com base nos recebimentos líquidos futuros esperados. $O$ lucro é mensurado através do crescimento do patrimônio líquido originado pela manipulação dos ativos. Sob esse prisma, os ativos de qualquer natureza são "recebíveis" esperados para fluir para a empresa período a período.

Dentro deste conceito de lucro e patrimônio, a Gestão Econômica, ao contrário de outros modelos contábeis gerenciais, reconhece que o lucro não ocorre apenas por ocasião da venda, mas é gerado sempre que haja de fato uma criação de valor, uma variação patrimonial produzida por um evento decorrente de uma decisão da empresa ou por impactos de variações do ambiente econômico.

Nessa concepção, a variação da riqueza da empresa, expressa pelo resultado gerado por um evento está representada na Figura 1.

Figura 1: O Resultado gerado pelo evento Investimento na Marca

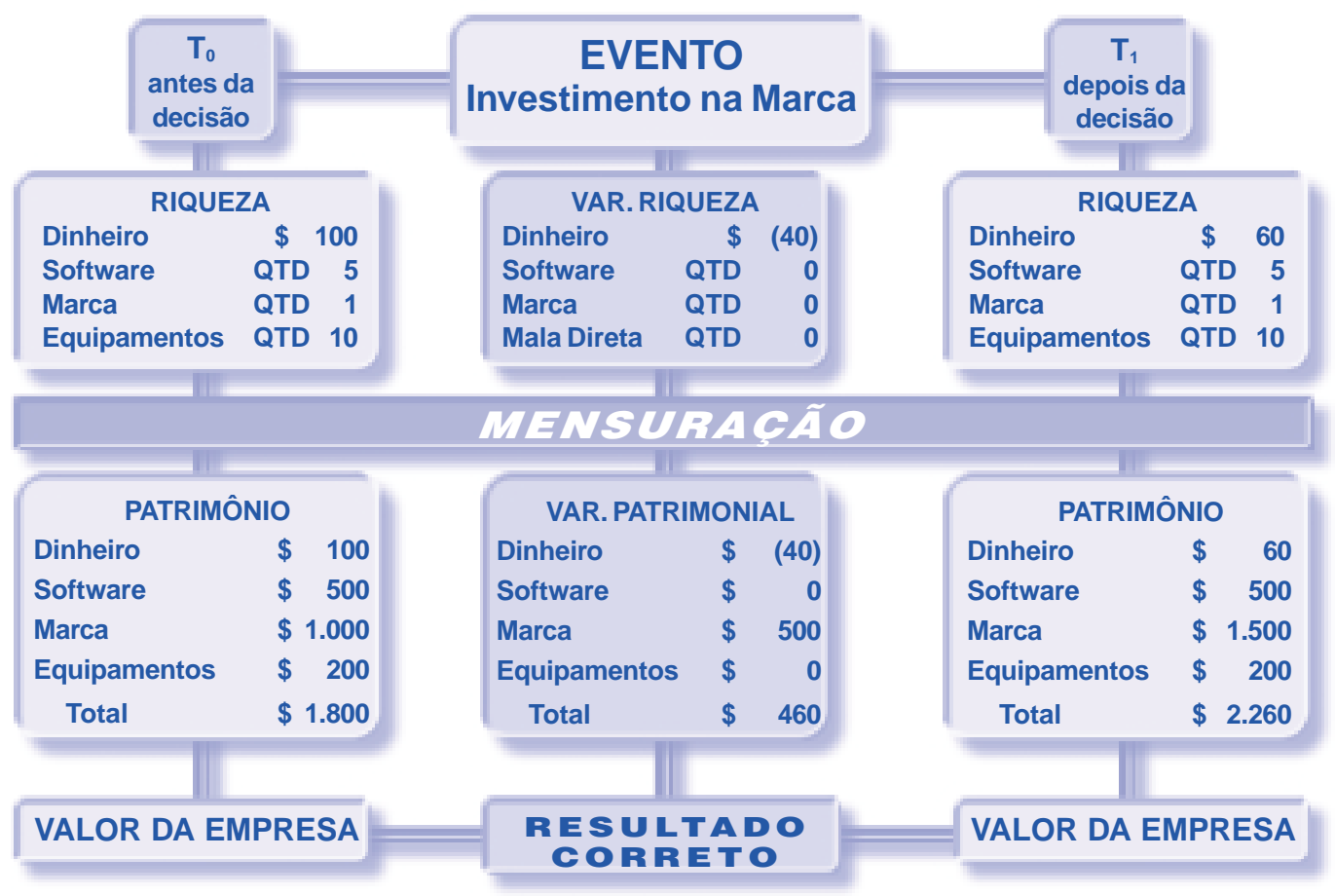

Fonte: Adaptado de Catelli, 1999

\footnotetext{
${ }^{11}$ Ver Catelli et al (1999, p.9).
} 
Conforme a figura, a variação no valor dos ativos da empresa, que constituem o seu patrimônio, é provocada pelo evento "investimento na marca". Assim, entre $T_{0}$ e $T_{1}$, o evento consumiu recursos (dinheiro) no valor de $\$ 40$ e produziu benefícios (marca) no valor de $\$ 500$, provocando uma variação na riqueza da empresa no valor de $\$ 460$, que constitui o resultado do evento. Essa variação, como valor criado pelo evento, está incorporada no patrimônio da empresa, aumentando o seu valor, de $\$ 1.800$ para $\$ 2.260$.

Esse método de mensuração difere dos sistemas tradicionais, que reconhecem apenas o valor do recurso consumido, como despesa, diminuindo o valor do patrimônio, ou, na melhor das hipóteses, diferem o gasto, registrando-o como ativo, sem alteração no valor do patrimônio.

Esse exemplo do investimento na marca não foi escolhido ao acaso, uma vez que, nas empresas voltadas para a Internet, e em fase de lançamento e crescimento, e cujo produto, como visto, é a própria interatividade, os gastos de marketing são muito volumosos e cruciais para o seu sucesso. Os sistemas tradicionais, ao não reconhecerem a variação de riqueza representada pelos benefícios do evento, líquidos dos seus custos - e ao considerar apenas os custos - negligenciam o todo da decisão que gerou o evento, visando ao resultado e aumento de riqueza da empresa. Com isso, tais sistemas falseiam a realidade patrimonial atual da empresa e tornam impossível avaliar a racionalidade da sua decisão.

Assim, para a Gestão Econômica, uma empresa da nova economia que investe maciçamente em marketing e tem seu investimento reconhecido pelo mercado está, de fato, gerando valor e obtendo resultado na forma do valor presente do fluxo de resultados futuros a serem gerados por esse investimento acertado.

Para a gestão das empresas, tanto da nova economia como da economia tradicional, o fato de suas decisões mais cruciais, como o investimento em marketing, não terem respaldo da mensuração pela contabilidade gerencial priva-as de um instrumento essencial à sua eficácia.

A Gestão Econômica, ao possibilitar a identificação da riqueza gerada pela empresa, nas decisões voltadas para o futuro, proporciona à gestão esse instrumento de mensuração, pelo qual o acerto e a racionalidade das decisões dos gestores podem ser avaliados. Com isso, tais decisões podem ser simuladas e planejadas, inclusive com relação ao seu impacto no valor das ações da empresa no mercado de capitais, como se verá posteriormente.

É claro que a Gestão Econômica não ignora que o reconhecimento do valor presente de benefícios futuros e, portanto, incertos, implica estimativas e avaliações de certo modo subjetivas. Entretanto, estimativas são necessárias, assim que se começa a considerar o futuro, e, sem este, o presente também não tem qualquer significado, nem para a vida humana nem para os negócios.

Por isso, Bodenhorn (1961, p. 585-6) defende, há quatro décadas, que a contabilidade reconheça ganhos e perdas de capital tão logo a administração identifique que eles ocorreram, a fim de que os ativos da empresa possam ser continuamente avaliados:

O contador pode objetar que isso é uma coisa excessivamente difícil de fazer (altamente subjetiva), uma vez que isso envolve uma estimativa contínua dos retornos futuros, que serão obtidos em cada projeto. Eu posso argüir somente que é o negócio da administração fazer tais estimativas, e tais estimativas são também continuamente feitas pelos investidores. (...) $\mathrm{O}$ objetivo do contador de um valor estável para os ativos da firma é na melhor das hipóteses uma miragem. O fato é que o valor da firma, e o valor dos ativos da firma, flutuam constantemente através do tempo, assim que os lucros futuros pareçam ser maiores ou menores. Um procedimento contábil que ignora esse fato óbvio é simplesmente um exercício contábil que não teria interesse para o homem de negócios ${ }^{12}$.

Ao incorporar critérios econômicos na visão do patrimônio como potencial de riqueza, a Gestão Econômica prioriza não apenas a perspectiva temporal - a interação presente-futuro, como antecipação dos resultados das decisões - mas, com isso, também a interação contínua do sistema empresa com o sistema mercado e, em geral, com o macro-sistema ambiente.

12 Ver, a esse respeito, também Catelli et al (1999, p. 12). 
Por isso, a Gestão Econômica, na mensuração do patrimônio e lucro da empresa, utiliza parâmetros econômicos de mercado, como custos de oportunidade, equivalência de capitais no tempo, preços de transferência e moeda constante.

Essa visão interativa do patrimônio é, como já comentado, particularmente apta à análise e entendimento das empresas da nova economia e dos projetos voltados para a Internet das empresas tradicionais. De fato, a visão integrativa do patrimônio, que evolui desde o início da contabilidade e se aplica a qualquer tipo de empresa $^{13}$, é ressaltada pela nova dimensão da interatividade trazida pela Internet a partir das empresas e projetos da nova economia, com impactos abrangentes em toda a economia e em todas as organizações.

A expressão da interatividade no processo de gestão da empresa, tal como conceituado na Gestão Econômica, será abordada a seguir.

\section{3 - Gestão Interativa por Feedforward}

A interatividade entre os múltiplos elementos e sistemas da empresa é alcançada na Gestão Econômica mediante o sistema de gestão, constituído pelo processo decisório de planejamento, execução e controle, pelo qual a empresa parte de sua situação atual e busca uma situação futura desejada.

No caso das empresas da Internet - e nos "projetos.com" das empresas tradicionais - a novidade e pouca previsibilidade do ambiente fazem com que não haja tantos parâmetros pré-definidos para decisões, o que confere ao processo de gestão um caráter pouco repetitivo e extremamente dinâmico e inovador.

Por isso, o sistema de gestão das empresas da nova economia é uma constante interação entre planos, implementações e reajustes - ou seja, um processo contínuo de renovação por realimentação ou feedback. Na nova economia, esta interação e dinamismo são intensos e o processo cheio de surpresas, exigindo grande flexibilidade e velocidade. Recentemente, no final de 1999, por exemplo, o mercado de provedores de Internet no Brasil foi sacudido e reconfigurado abruptamente com a introdução dos sites gratuitos.

$\mathrm{Na}$ Gestão Econômica, é fundamental esta visão interativa do processo de planejamento, execução e controle. O planejamento e controle são inseparáveis e apenas didaticamente distintos, ambos integrados pelo feedback (Oliveira 1999, p. 162 s). Conforme Catelli (1999, p.128) o " processo de gestão econômica é, na realidade, um grande processo de controle, que tem por objetivo assegurar a eficácia empresarial".

Mediante o feedback contínuo, o processo integrado de planejamento, execução e controle possibilita a identificação e acumulação do impacto econômico de cada evento no resultado global da organização. Com isso, as decisões são continuamente avaliadas e revistas, bem como os próprios planos, diante das intensas mudanças do ambiente.

Por isso, para além da ótica do feedback como realimentação de um processo mediante revisão ou reexame do ocorrido, o processo de gestão no ambiente em mudança contínua, como o da nova economia, é cada vez mais experimentado e concebido como uma série sucessiva de esforços, objetivos e resultados projetados, a partir de cuja antecipação o controle é exercido. Caracteriza-se, assim, o processo de feedforward, conceito utilizado no controle de sistemas físicos e de redes neurais artificiais e estendido à gestão ${ }^{14}$. $O$ controle por antecipação, próprio do conceito de feedforward, inclui, naturalmente, o controle por realimentação a partir do ocorrido, próprio do conceito de feedback.

A visão do processo de gestão como feedforward contínuo, realçada pelo modelo de gestão das empresas de capital intelectual intensivo da nova economia, caracteriza-as como "learning organizations", cuja capacidade de geração de riqueza aumenta na proporção dos erros e acertos de seu aprendizado contínuo.

Esse processo é centrado na interatividade, ressaltada pelas "organizações digitais", as quais, como diz John Chambers, da Cisco, "devem se basear na transformação, não na estabilidade; em torno de redes, não em hierarquias rígidas; na

\footnotetext{
${ }^{13}$ Ver Santos e Ponte (1998, p. 705-721).

14 A propósito do conceito de feedforward ver, por exemplo, Learning stochastic feedforward networks. Dept. of Computer Science, University of Toronto. www.cs.toronto.edu. Ver também Kaplan \& Cooper (1998, passim).
} 
interdependência com parceiros, não na autosuficiência. Estar em rede significa compartilhar informação e poder" (Gurovitz, 1999b, p. 129).

Para propiciar a integração do processo de gestão, a Gestão Econômica desenvolve modelos de decisão que possibilitam, em todos os níveis gerenciais, a simulação do impacto econômico das diversas alternativas de decisão, bem como a identificação e avaliação do impacto da decisão realizada no resultado do todo da empresa.

Os modelos de decisão constituem, assim, um instrumento de gestão compartilhada por feedforward, uma vez que permitem a interatividade entre os diversos gestores e áreas de atividade e entre estas e o ambiente em constante mudança. Com efeito, os modelos de decisão permitem ao gestor identificar o valor gerado em cada decisão e converter objetivos qualitativos, mensurados por índices (por exemplo, melhorar em $10 \%$ o índice de qualidade ou aumentar em 30\% o número de acessos ao site da empresa) em parâmetros de resultado econômico, medindo e comparando os benefícios e custos envolvidos em cada decisão, integrada no processo interativo de gestão.

Somente um modelo de gestão por resultados, exercido em todos os níveis gerenciais, possibilita a interatividade eficaz dos diversos centros decisórios da empresa entre si e com o ambiente e o seu crescimento integrado, por feedforward.

Ou seja, a interatividade tecnológica só terá sentido na empresa se o modelo de gestão assegurar a interatividade gerencial voltada para a eficácia e para o resultado econômico.

A identificação do valor a cada decisão possibilita, ainda, que a avaliação dos gestores seja efetuada por fatores que eles efetivamente controlam. Isto evita os freqüentes mal-entendidos e conflitos de interesse dos sistemas de avaliação tradicionais. Esta clareza na avaliação de desempenho se torna fundamental numa economia cada vez mais centrada no "trabalhador do conhecimento" e cujo sistema de compensações enfatiza a criação de valor, o desempenho e a busca de resultados.

O processo de gestão compartilhada por feedforward contínuo, próprio da Gestão Econômica, coloca, assim, a empresa no ambiente interativo da nova economia como "learning organization" mediante a renovação contínua de sua atividade pelo planejamento, execução e controle integrado, abrangendo todos os níveis gerenciais e todas as decisões, desde a transação até as decisões mais abrangentes. Somente um tal processo interativo de gestão poderá capacitar a empresa da atualidade a exercer com eficácia e continuidade suas atividades no ambiente de intensas e contínuas mudanças, criado pelo surgimento da Internet.

\section{2 - A INTERNET E A CONTABILIDADE FINANCEIRA}

\section{1 - Contabilidade Financeira das Empresas de Internet}

Já há vários anos, analistas e estudiosos do mercado de capitais têm apontado as deficiências da contabilidade tradicional em gerar e comunicar informações relevantes para os investidores. Restrita aos valores nominais dos eventos ocorridos e comprovados, a contabilidade tem falhado na determinação do valor dos ativos das empresas, em especial dos ativos intangíveis e do valor das expectativas futuras incorporado nesses ativos.

Bennet Stewart (1993, p.9) chega a comentar que os contadores podem elaborar as demonstrações contábeis ou para os credores ou para os investidores - ou seja, para avaliar a dívida da empresa ou o seu valor de mercado - mas que não podem fazer ambos ao mesmo tempo. Nesse impasse, a contabilidade teria se decidido a fazer seus balanços com vista aos credores, numa perspectiva de liquidação imediata dos ativos, como se a empresa estivesse sempre às vésperas da falência.

Essas e outras discrepâncias tornaram-se dramaticamente visíveis com a trajetória das empresas de alta tecnologia no mercado de capitais, em particular as relacionadas com a Internet ${ }^{15}$. Por exemplo, a Cisco, no balanço de 1999, tinha ativos no valor de US $\$ 14,7$ bilhões, mas suas ações valiam US $\$ 470$ bilhões, ou seja, 32 vezes o valor de balanço. No caso da Yahoo!, a relação era de 36 vezes (com valor de mercado de US\$ 68,3 bilhões e ativos de US\$1,9 bilhão) ${ }^{16}$.

\footnotetext{
15 É claro que, como nota Thomas Stewart (1998, p. 208), o analista financeiro tem que levar em consideração a evolução das empresas no mercado ao longo do tempo. No caso das empresas de Internet, "pelo menos até que as companhias de intensos ativos intangíveis tornem-se velhas e sábias, como a Coca-Cola, o seu valor parece ser intrinsecamente volátil”. Essa volatilidade se exprimiu mais claramente no início deste ano, em que, por exemplo, na segunda semana de abril, o índice da bolsa de tecnologia Nasdaq caiu 25,31\%, para imediatamente subir 14\% (Ver Folha de São Paulo, 19/04/2000, $2^{\circ}$ Caderno, p. 1).

${ }^{16}$ Ver LOPES, Mikhail. Por que as contas não fecham. In: Exame. Edição 714, ano 34, nº 10, 17/05/2000, p.143.
} 
A contabilidade gerencial, na ótica da Gestão Econômica, oferece, sem dúvida, um caminho de superação dessas graves discrepâncias, como já comentado. Tem-se à frente, entretanto, o trabalho complexo, mas necessário, de aproximar os procedimentos da contabilidade financeira dos conceitos econômicos de valor.
Tornou-se, de fato, mais premente, com o advento da empresas da Internet e sua repercussão no mercado de capitais, a necessidade, já há muito detectada pelos estudiosos, de a contabilidade compatibilizar os interesses de seus diversos usuários, expressos em diversos tipos de informação, como elencado por ludícibus (1997, p.21), no quadro apresentado na Figura 2.

\begin{tabular}{|c|c|}
\hline \multicolumn{2}{|c|}{ Figura 2: Metas dos Diversos Tipos de Usuário } \\
\hline $\begin{array}{l}\text { Usuário da } \\
\text { Informação Contábil }\end{array}$ & $\begin{array}{l}\text { Meta que Desejaria Maximizar ou } \\
\text { Tipo de Informação mais Importante }\end{array}$ \\
\hline Acionista minoritário & fluxo regular de dividendos \\
\hline Acionista majoritário & fluxo de dividendos, valor de mercado da ação, \\
\hline ou com grande participação & lucro por ação. \\
\hline Acionista preferencial & fluxo de dividendos mínimos ou fixos. \\
\hline Emprestadores em geral & geração de fluxos de caixa futuros suficientes \\
\hline & $\begin{array}{l}\text { para receber de volta o capital mais os juros, } \\
\text { com segurança. }\end{array}$ \\
\hline Entidades governamentais & valor adicionado, produtividade, lucro tributável. \\
\hline Empregados em geral, como & fluxo de caixa futuro capaz de assegurar bons \\
\hline assalariados & $\begin{array}{l}\text { aumentos ou manutenção de salários, com } \\
\text { segurança; liquidez. }\end{array}$ \\
\hline Média e alta administração & $\begin{array}{l}\text { retorno sobre o ativo, retorno sobre o patrimônio } \\
\text { líquido; situação de liquidez e endividamento } \\
\text { confortáveis. }\end{array}$ \\
\hline
\end{tabular}

O problema dessa compatibilização é que a informação diferenciada, para ser útil aos diversos tomadores de decisão, deverá combinar ao mesmo tempo as qualidades da confiabilidade e da relevância. Como esclarecem Hendriksen e van Breda (1991, p. 132), a confiabilidade inclui as qualidades da verificabilidade, da neutralidade e da fidelidade representativa; as qualidades que constituem a relevância são a tempestividade (timeliness), o valor de feedback e o valor preditivo da informação.

Do ponto de vista conceitual, essa compatibilização, como anteriormente tratado, encontra uma solução no Sistema de Gestão Econômica, que une os princípios e critérios de relevância econômica com a confiabilidade do rigor metodológico.

Entretanto, o dilema dos contadores, mesmo que superado conceitualmente e na prática da contabilidade gerencial econômica, permanece crucial na contabilidade financeira, dentro das normas atuais. Como observa Martins, apud Lopes (2000, p.145), referindo-se especificamente às empresas da Internet:

Os balanços são muito objetivos. Para que eles representassem a perspectiva de uma empresa dar lucro no futuro, precisariam basear-se em critérios mais subjetivos (...). Mas aí os balanços dariam margem a ainda mais malabarismos contábeis (...). Qual contador iria querer assinar um balanço desses?

Esse dilema se torna mais grave, como observa Bennet Stewart (1993, p.7), quando se sabe que um contador pode ser acionado judicialmente, sobretudo nos Estados Unidos, se superavaliar os lucros. Infelizmente, após o aparecimento das empresas da Internet, a alternativa a esse risco parece ser resignarse a produzir demonstrações contábeis que, para efeitos vitais do mercado, são completamente inúteis.

A questão que se coloca, portanto, é se já existem 
metodologias reconhecidas e práticas contábeis aceitas pelos órgãos normativos que possibilitem ao contador incluir estimativas e outras mensurações subjetivas na informação contábil.

De fato, o mercado já oferece exemplos de aproximação prática entre as abordagens da contabilidade gerencial e as da contabilidade financeira. King \& Henry (1999, p. 3237) comentam que a base para valoração dos ativos das empresas de alta tecnologia, quando da oferta inicial de ações (IPO), são seus ativos intangíveis, que não podem constar nos balanços enquanto os princípios contábeis geralmente aceitos não forem modificados. Contudo, comentam os autores:

Os banqueiros hoje estão fazendo empréstimos utilizando os ativos intangíveis como garantia. Se esses documentos são suficientemente confiáveis para os banqueiros, então parece lógico que essas valorações sejam igualmente confiáveis para evidenciação nas demonstrações contábeis para os investidores individuais. As avaliações dos ativos intangíveis são relevantes e confiáveis.

O próprio FASB, em diversos pronunciamentos, tem se direcionado nesse sentido, como observam Catelli et al (1999, p.11-12):

A importância da utilização de critérios econômicos na gestão empresarial, apesar das dificuldades de se medir aspectos incertos e subjetivos, já vem sendo considerada em algumas práticas da própria contabilidade societária. Assim, alguns ativos tradicionalmente mensurados pelo custo, hoje são contabilizados pelo fair value, ou seu valor de mercado, conforme o FAS no 115 prescreve para os investimentos em títulos (debt and equity securities). Tratamento similar se observa para os derivativos, incluídos nos balanços a partir de 15/06/99, conforme o FAS 133. Transparece, assim, uma tendência consistente na contabilidade americana para a contabilização pelo critério mark to market.

Além disso, no caso da contabilização dos planos recompensas de empregados na forma de opções em ações, o FAS 123 (Accounting for Stock-based Compensation) encoraja a adoção do método do fair value. Por esse método, o custo desses planos de recompensa para a empresa não é medido nem sequer pelo valor de mercado da opção na data da concessão do benefício ao empregado, mas sim com base no seu valor futuro. Na determinação desse valor, utilizam-se os métodos estimativos de precificação das opções reconhecidos pelo mercado, que incluem, entre outros fatores, a volatilidade das ações, a vida esperada das opções, a taxa livre de risco e os dividendos esperados durante a vida da opção.

Essas metodologias e práticas preditivas, embora de uso ainda incipiente na contabilidade, são de uso habitual no mercado de capitais. Isso explica o aparente paradoxo de que a publicação das demonstrações contábeis, apontando lucro (ou prejuízo) das empresas não provoca variação no preço das suas ações, como atestado por várias pesquisas nos Estados Unidos ${ }^{17}$. Acreditava-se, por isso, que o lucro contábil era irrelevante para a determinação do preço das ações.

Entretanto, Ball \& Brown (1968) provaram que o que de fato ocorre é que o mercado, mediante uma série de informações diversas e contínuas, é capaz de prever o lucro que a empresa terá no período e incorporar essa expectativa nas variações cotidianas dos preços das ações. Assim, quando a demonstração contábil é publicada no final do exercício, o lucro ou prejuízo já não provoca variação significativa na cotação da ação, uma vez que o balanço apenas confirma o que o mercado já sabia.

Hendriksen e van Breda (1991, p. 174) comentam que o mercado dispõe, além das publicações contábeis, de outras informações, tais como informações econômicas gerais e setoriais, relatórios e artigos financeiros em jornais especializados, entrevistas de executivos com analistas financeiros, com investidores ou com representantes de grupos da sociedade, comunicados de imprensa etc.

Ora, essas informações são convertidas pelos investidores em mensurações estimativas que influenciam continuamente o valor das ações. Uma vez que tais informações chegam aos investidores mais rapidamente que as informações contábeis, ocorre a antecipação na valoração das ações e a contabilidade financeira passa a ter valor apenas como confirmação oficial da informação já conhecida. Por outras palavras, no mercado já ocorre uma aproximação constante entre os critérios da contabilidade econômica gerencial e as informações, mesmo que limitadas, da contabilidade financeira.

${ }^{17}$ Ver Hendriksen e van Breda (1991, p. 169-187) e Watts \& Zimmerman (1986, p. 15-70). 


\section{2 - Internet e Contabilidade Interativa}

$O$ advento da Internet, com seus imensos recursos tecnológicos para aumento da velocidade e interatividade na disseminação da informação é, sem dúvida, uma oportunidade para a atenuação da defasagem, pelo menos temporal, entre a contabilidade financeira e a contabilidade gerencial. Com a superação da defasagem temporal, parece ser inevitável uma aproximação conceitual, como propugnado neste trabalho.

É nessa direção que parece caminhar a atenção dos órgãos normativos nacionais e internacionais, ao tratarem das implicações da Internet para a contabilidade.

Como destaca o IASC no seu Business Reporting on the Internet (1999, p.37):

Com as demonstrações tradicionais baseadas na imprensa, é muito caro distribuir mais do que um demonstrativo anual e demonstrativos trimestrais para todos os acionistas. O impulso tecnológico, como o da Internet, modifica radicalmente a economia da distribuição da informação. Em um nível simples, a Web pode ser utilizada para coletar os endereços de e-mail dos acionistas, clientes, fornecedores e navegadores interessados. Todos os comunicados de imprensa, resultados trimestrais e informações sobre novos produtos podem ser enviados para a lista de e-mails a um custo realmente zero.
Vários países têm estimulado experiências de divulgação da informação contábil via Internet, como por exemplo, o Projeto Faux.com do FASB. Esse projeto é um modelo de demonstração contábil que utiliza recursos específicos da Internet, e objetiva mostrar às empresas novas formas de apresentar essas demonstrações, uma vez que estas freqüentemente usam a Internet apenas para duplicar a forma tradicional das demonstrações impressas. O chefe do projeto do FASB, Wayne Upton, comenta que não há muito futuro na simples duplicação da forma tradicional de apresentação dos balanços num site da Web. O uso dos recursos de interatividade da Internet (sobretudo por meio dos links da linguagem HTML) "dá às empresas a oportunidade de integrar melhor os elementos do pacote das demonstrações. Os usuários podem utilizar mapas e links do site para navegar no pacote inteiro, procurar áreas-chave de seu interesse, acompanhar a discussão de um item específico de uma seção para outra e capturar informação chave em formas adaptáveis ao seu uso posterior" (The CPA Journal, maio/1998, p.9).

Para investigar o estado atual da informação contábil via Internet, o IASC realizou em 1999 uma pesquisa abrangendo as 30 maiores empresas de cada país, listadas no Dow Jones Global Index, num total de 22 países, inclusive o Brasil. Um resumo simplificado dessa pesquisa consta na Figura 3.

\begin{tabular}{|c|c|c|c|c|c|c|c|c|c|c|c|c|}
\hline \multicolumn{13}{|c|}{ Figura 3: Informação Contábil Interativa na Internet - 30 maiores empresas de cada país } \\
\hline \multirow{3}{*}{ Países } & \multirow{2}{*}{\multicolumn{2}{|c|}{$\begin{array}{c}\text { Não possuem } \\
\text { site naWeb }\end{array}$}} & \multirow{2}{*}{\multicolumn{2}{|c|}{$\begin{array}{c}\text { Não possuem } \\
\text { informações } \\
\text { contábeis no Site }\end{array}$}} & \multicolumn{6}{|c|}{ Possuem informações contábeis no Site } & \multirow{2}{*}{\multicolumn{2}{|c|}{ TOTAL }} \\
\hline & & & & & \multicolumn{2}{|c|}{$\begin{array}{l}\text { Sem interatividade } \\
\text { Somente } \\
\text { download }\end{array}$} & \multicolumn{2}{|c|}{\begin{tabular}{c|} 
Com \\
interatividade \\
Usa links
\end{tabular}} & \multicolumn{2}{|c|}{ Subtotal } & & \\
\hline & Quant. & $\%$ & Quant. & $\%$ & Quant. & $\%$ & Quant. & $\%$ & Quant. & $\%$ & Quant. & $\%$ \\
\hline Alemanha & 0 & $0 \%$ & 7 & $23 \%$ & 5 & $17 \%$ & 18 & $60 \%$ & 23 & $77 \%$ & 30 & $100 \%$ \\
\hline Austrália & 0 & $0 \%$ & 6 & $20 \%$ & 7 & $23 \%$ & 17 & $57 \%$ & 34 & $80 \%$ & 30 & $100 \%$ \\
\hline Brasil & 2 & $7 \%$ & 12 & $40 \%$ & 3 & $10 \%$ & 13 & $43 \%$ & 16 & $53 \%$ & 30 & $100 \%$ \\
\hline Canadá & 0 & $0 \%$ & 2 & $7 \%$ & 5 & $17 \%$ & 23 & $76 \%$ & 28 & $93 \%$ & 30 & $100 \%$ \\
\hline Chile & 14 & $47 \%$ & 6 & $20 \%$ & 4 & $13 \%$ & 6 & $20 \%$ & 10 & $33 \%$ & 30 & $100 \%$ \\
\hline Coréia do Sul & 4 & $13 \%$ & 8 & $27 \%$ & 2 & $7 \%$ & 16 & $53 \%$ & 18 & $60 \%$ & 30 & $100 \%$ \\
\hline Espanha & 8 & $27 \%$ & 11 & $37 \%$ & 2 & $7 \%$ & 9 & $29 \%$ & 11 & $36 \%$ & 30 & $100 \%$ \\
\hline Estados Unidos & 0 & $0 \%$ & 3 & $10 \%$ & 2 & $7 \%$ & 25 & $84 \%$ & 27 & $91 \%$ & 30 & $100 \%$ \\
\hline Inglaterra & 1 & $3 \%$ & 11 & $37 \%$ & 0 & $0 \%$ & 18 & 605 & 18 & $60 \%$ & 30 & $100 \%$ \\
\hline Itália & 5 & $17 \%$ & 13 & $43 \%$ & 2 & $7 \%$ & 10 & $33 \%$ & 12 & $40 \%$ & 30 & $100 \%$ \\
\hline Japão & 2 & $7 \%$ & 8 & $27 \%$ & 5 & $17 \%$ & 15 & $50 \%$ & 20 & $67 \%$ & 30 & $100 \%$ \\
\hline México & 6 & $20 \%$ & 3 & $10 \%$ & 2 & $7 \%$ & 19 & $63 \%$ & 21 & $70 \%$ & 30 & $100 \%$ \\
\hline \multicolumn{13}{|c|}{ Fonte: Adaptado de IASC (1999, p.51). } \\
\hline
\end{tabular}


A importância do uso da Internet para o mercado de capitais é ressaltada pela Bolsa de Valores de Toronto, ao tratar da evidenciação via Internet (IASC, 1999, p. 61):

Para o mercado de capitais a Internet pode ser o maior salto no fornecimento da informação e da análise, desde o advento das comunicações eletrônicas. Ela está colocando informação relevante ao alcance do toque dos dedos do investidor, instantaneamente e simultaneamente.

Mas a Internet também levanta desafios regulatórios. Em um mundo em que a informação está cada vez mais disponível, é mais importante do que nunca que ela seja precisa, tempestiva e atualizada.

O referido relatório do IASC destaca ainda que a informação via Internet poderia ser desenhada com vista à sua utilização pelo usuário último. Este deveria ter os dados necessários para interpretar toda a informação, por exemplo, as séries históricas dos preços das ações nos últimos 5 anos, de modo a não precisar recorrer às empresas intermediárias de análise para sua interpretação.

Uma implicação da informação contábil via Internet, conforme o mesmo texto do IASC (id., p.85) é que, " por definição, a informação eletrônica - pelo menos na Web - é de natureza global. A longo prazo, há espaço apenas para uma norma global de intercâmbio de informações contábeis e similares". Isso significa que o IASC teria que desenvolver um modelo de normas internacionais que excluísse as diferenças, ainda que pequenas das contabilidades nacionais, como ocorre atualmente. As empresas teriam a opção de apresentar a informação, ou conforme as normas nacionais ou no padrão de linguagem contábil global.

Embora os projetos dos órgãos normativos se refiram necessariamente à forma de apresentação das informações contábeis, é claro que a multiplicidade e a velocidade das informações on-line constituem um ambiente informativo que entremeia e combina informações hoje pertinentes apenas à abordagem gerencial e às informações oficiais da contabilidade financeira.

Os investidores, contadores, estudiosos da contabilidade e outros usuários serão cada vez mais estimulados, não apenas ao uso e ao aperfeiçoamento contínuo das técnicas e recursos da Internet para a comunicação, mas, necessariamente, à reflexão e ao aprofundamento conceitual constante, a fim de poder mensurar o valor preditivo, de feedback - e feedforward - da informação relevante. Ou seja, mediante a interatividade crescente, a Internet inegavelmente contribuirá para a diminuição da distância entre as duas abordagens, gerencial e financeira, das informações contábeis.

\section{CONCLUSÃO}

Os novos desafios ao sistema de informação gerencial e à contabilidade financeira surgidos pelo recente fenômeno da Internet no ambiente econômico, sugerem que a hipótese de uma nova "expansão construtiva" da Teoria da Contabilidade para o final deste século, levantada por Littleton \& Zimmerman, não pode deixar de ser considerada.

Entretanto, o fenômeno das empresas da nova economia, com suas demandas características de intenso dinamismo, conhecimento intensivo, gestão compartilhada e abertura para o futuro, já encontra respostas na nova contabilidade gerencial expressa nos critérios, conceitos e metodologia do Sistema de Gestão Econômica, que correspondem aos interesses dessas empresas e do mercado. Com efeito, esse sistema expressa as múltiplas interações entre os subsistemas da organização e entre esta e o macro-sistema econômico, caracterizando o modelo interativo da contabilidade gerencial, que muito terá a ganhar com o advento da Internet.

A velocidade, o dinamismo e os recursos tecnológicos da Internet, desde que utilizados pela contabilidade financeira, como ora estimulado pelos projetos de diversos órgãos normativos e por muitas empresas, conduzirá muito provavelmente a uma reaproximação entre a prática contábil financeira, a Teoria Contábil, a prática gerencial e o mercado de capitais. O uso crescente das informações on-line e suas respostas pelos usuários, em tempo real, constitui um processo, embora incipiente, que imprimirá à contabilidade financeira um caráter cada vez mais interativo.

Dentro dessas tendências, se a Internet vier a ter na economia uma importância semelhante à do início da Revolução Industrial - como aparentemente promete - a Teoria Contábil, na trajetória de sua origem, renovação e continuidade, poderá revigorar 
mais uma vez a prática contábil tradicional, em busca de novas abordagens para atender a essa nova transformação da realidade econômica.
Para uma abordagem da contabilidade definitivamente inseparável da interatividade, este trabalho pretende ter contribuído.

\section{REFERÊNCIAS BIBLIOGRÁFICAS}

ACKOFF, Russel L. Redesigning the future. New York: John Wiley \& Sons, 1974.

BALL, R. \& BROWN, P. An empirical evaluation of accounting income numbers. Journal of Accounting Research. ํㅜ 6. outono, 1968.

BODENHORN, Diran. An economist looks at industrial accounting and depreciation. The Accountig Review, vol XXXVI, no 4, p. 582-588, outubro, 1961.

CATELLI, Armando et. al. Gestão Econômica de investimentos em ativos fixos. In: Anais do VI Congresso Internacional de Custos. Braga, Portugal, set.1999.

CATELLI, Armando. A controladoria e a contabilidade gerencial na era da globalização. Transparências de apresentação no VI Congresso Brasileiro de Custos. São Paulo, junho de 1999.

Controladoria: uma abordagem da Gestão Econômica - GECON. São Paulo: Atlas, 1999.

DRUCKER, Peter F. Administrando para o futuro. Tradução de Nivaldo Montingelli Jr. São Paulo: Pioneira, 1992.

DRUCKER, Peter. O futuro já chegou. Exame. Ano 34, no 6, 22/03/2000, p. 112-.126.

DYSON, Peter. Dominando o internet information server. Tradução de Lávio Pareschi. São Paulo: Makron, 1998.

GECON. Sistema de Gestão Econômica. www.gecon.com.br.

GUERREIRO, Reinaldo. Modelo conceitual de sistema de informação de gestão econômica: uma contribuição à teoria da comunicação da contabilidade. Tese (Doutorado) - FEA/USP. São Paulo, 1989.

Um modelo de sistema de informação contábil para mensuração do desempenho econômico das atividades empresariais. Caderno de Estudos-FIPECAFI. № 4, março, 1992.

GUROVITZ, Hélio. Planeta e. In: Exame. Ano 32, ํo 12, 16 de junho de 1999a. p.148-159.

Gestão digital. In: In: Exame. Ano 33, no 16, 11 de agosto de 1999b. p.126-138.

HENDRICKSEN, E. S. \& VAN BREDA, M. F. Accounting theory. Chicago: Irwin, 1992.

IASC. Business reporting on the Internet. Novembro de 1999.

$|J| R \mid$, Yuri. The foundations of accounting measurement. Englewood Cliffs, NJ: Prentice Hall, 1967.

INFORMATIONWEEK. GM will use technology to know its costumers. № 763, 29/11/99, p.153-154.

IUDÍCIBUS, Sérgio de. Teoria da Contabilidade. 5a edição. São Paulo: Atlas, 1997.

JAMSA, Kris et al. Programando para Word Wide Web. Tradução de Maria Cláudia S. R. Ratto. São Paulo: Makron Books,1999.

JOHNSON, T. \& KAPLAN, R. Relevance lost. Boston:Harward Business School, 1990.

KING, Alfred M. \& HENRY, Jay M. Valuing intangible assets through appraisals. Strategic Finance. Vol. 81, edição 5, novembro, 1999.

LITTLETON, A. C. \& ZIMMERMAN, V. K. Accounting theory: continuity and change. Englewood Cliffs: Prentice-Hall, 1962.

LOCKE, Robert L Factoring American business school education into the revolution in interactive information technology. Forthcoming in "The foundations of management knowledge”. 1999. www.qub.ac.uk/mgt/cmk/lockpapr.htm.

LOPES, Mikhail. Por que as contas não fecham. 
Exame. Edição 714, ano 34, № 10, 17/05/2000. p.142-144.

MARTINS, Eliseu. Contribuição à avaliação do ativo intangível. Tese (Doutoramento) - FEA/USP. São Paulo, 1972.

MATESSICH, Richard. Accounting and analytical methods. Homewood, Illinois: Irwin, 1964.

MINTZBERG, Henry; QUINN, James B. The strategy process. $3^{\mathrm{a}}$ edição. Upper Saddle River, New Jersey: Prentice-Hall, 1996.

OLIVEIRA, Antônio B. Silva. Contribuição à formulação de um modelo decisório para intangíveis por atividade - uma abordagem de Gestão Econômica. Tese (Doutoramento) - FEA/USP. São Paulo, 1999.

PARISI, Cláudio et al. Impactos da Internet na evolução da ciência contábil. Revista de Contabilidade do CRC-SP. Ano 1, no 1, abril de 1997.

PEREIRA, Carlos A. Estudo de um modelo de avaliação de desempenhos para Gestão Econômica. Dissertação (mestrado) -FEA/USP. São Paulo, 1993.

PETERSON, Elen. Já imaginou navegar na internet pela geladeira? VEJA Vida Digital. Internet 2000. Ano 33, no 1645, p. 42-44.

REBOUÇAS, Lídia. Canibalize-se. Exame. Edição 710, ano 34, no 6, 22/03/2000. p.132-138.

SANTOS, Edilene S. \& PONTE, Vera. Gestão Econômica: um modelo para a integração sistêmica da empresa. In: Anais do V Congresso Brasileiro de Gestão Estratégica de Custos. v. 2, p. 705-721. Fortaleza, set, 1998.

SANTOS, Edilene S. Objetividade $x$ relevância: o que o modelo contábil deseja espelhar? Caderno de
Estudos-FIPECAFI, v. 10, № 18, p. 9-19, maio/ agosto, 1998.

STEWART, Bennet. Market myths. In: CHEW, Donald $\mathrm{H}$. The new corporate finance: where theory meets practice. New York: McGraw-Hill, 1993.

STEWART, Thomas A. Real assets, unreal reporting. Fortune. 6 de julho, 1998. p.207-208.

TEIXEIRA, Sérgio Jr. Vida e morte na Internet. Exame. Ano 34, no 15, 26/07/2000, p. 42-52.

THE CPA JOURNAL. FASB explores making financial statements more useful to investors. Maio, 1998, p.9.

TICHY, Noel M. \& SHERMAN, Stratford. Controle seu destino antes que alguém o faça - como Jack Welch está transformando a General Electric na empresa mais competitiva do mundo. Tradução de Claudiney Fullman. São Paulo: Educator, 1995.

UNIVERSITY OF TORONTO. Dept. of Computer Science. Learning stochastic feedforward networks. www.cs.toronto.edu.

VASCONCELOS, Carlos. TCS prepara acesso à Internet pelo orelhão. Gazeta Mercantil. 16/02/2000, p. C3.

VEJA Vida Digital. Internet 2000. Ano 33, no 1645 , 19/04/2000.

VIEIRA, Fabrício. Para Citi, só sobrarão $20 \%$ da Internet. Folha de São Paulo. 12/04/200. 2º Caderno, p. 1.

WATTS, Ross L. \& ZIMMERMAN, Jerold L. Positive accounting theory. Englewood Cliffs: Prentice-Hall, 1986.

WOMACK, James P. \& JONES, Daniel T. A mentalidade enxuta nas empresas. Rio de Janeiro: Campus, 1998. 